\title{
A Brain-Inspired Dynamic Environmental Emergency Response Framework for Sudden Water Pollution Accidents
}

\author{
Ying Zhao, Yilin Pan, Wensong Wang $\mathbb{1}$ and Liang Guo *
}

check for updates

Citation: Zhao, Y.; Pan, Y.; Wang, W.; Guo, L. A Brain-Inspired Dynamic Environmental Emergency Response Framework for Sudden Water Pollution Accidents. Water 2021, 13, 3097. https://doi.org/10.3390/ w13213097

Academic Editor: Xiaobin Tang

Received: 10 October 2021

Accepted: 2 November 2021

Published: 3 November 2021

Publisher's Note: MDPI stays neutral with regard to jurisdictional claims in published maps and institutional affiliations.

Copyright: (c) 2021 by the authors. Licensee MDPI, Basel, Switzerland. This article is an open access article distributed under the terms and conditions of the Creative Commons Attribution (CC BY) license (https:/ / creativecommons.org/licenses/by/ $4.0 /)$.
Department of Environment, Harbin Institute of Technology, Harbin 150001, China; zhaoying@hit.edu.cn (Y.Z.); page10rock@163.com (Y.P.); wwsnbts@163.com (W.W.)

* Correspondence: guoliang0617@hit.edu.cn

\begin{abstract}
Sudden water pollution accidents happen frequently in China, and the number of treated accidents is low, due to the slow response speed. In addition, there is a lack of decision support systems that can follow up the whole process instead of just giving a one-time method. This study constructs a framework suitable for China that has both the ability of quick responses and full-time dynamic decision support, such as an experienced expert, while not being affected by pressure, to be used an emergency response for sudden water pollution accidents. To allow new decisionmakers to integrate into this professional decision-making role more quickly, a brain-inspired system is realized through combining the machine learning algorithm KNN and the idea of iteration and dynamic programming. The feasibility of our framework is further tested through a major water pollution happened recently. The results show that this framework can be well connected with the emergency response technology system that has been completed before, while also supporting the rapid and robust decision making such as the decisionmaker's second brain, reducing the demand for professional background and experience of emergency decisionmakers, thus effectively shorten the waiting period for response.
\end{abstract}

Keywords: brain-inspired; emergency response framework; sudden water pollution; dynamic reasoning; whole process; decision driven by big data analysis

\section{Highlights}

1. A brain-inspired dynamic environmental emergency response framework for sudden water pollution accidents was built.

2. The whole process of dynamic reasoning besides the fast matching of cases like a human was realized, while not being distorted by human feelings.

3. The standards, methods, and algorithms of the framework were given based on big data analysis of historical pollution cases.

4. The feasibility and robustness of the framework was tested through the biggest tailings pond leakage accident in China in 20 years.

\section{Introduction}

\subsection{Sudden Water Pollution Accidents in China}

Sudden water pollution accidents directly threaten human health and the safety of the environment. Due to the complexity and emergency of sudden water pollution accidents, the rapid identification and mitigation of risks in environmental emergency responses are the primary goals. When dealing with sudden water pollution accidents, a proper quick-response framework can optimize the emergency response to the greatest extent and can choose the most effective solution with the lowest negative impact and the shortest response time.

In China, pollution accidents now are given priority to water pollution. According to statistics, since China's reform and opening up in 1978-2020, a total of 1475 water pollution 
incidents occurred, and the situation of water environment protection is still severe.As in Figure 1, chemicals caused the most pollution, with 889 cases accounting for $60.27 \%$ of the total number, and heavy metal and tailings pond pollution was the least, accounting for 97 cases $(6.57 \%)$. Spatially, the pollution sources are mainly distributed in rivers and along rivers, which can easily affect the whole basin. In terms of time trend, the number of water pollution incidents was increasing before 2010 and showed a downward trend after 2010. In terms of severity, general incidents accounted for the majority $(72.20 \%)$, but there were still a few serious incidents $(5.76 \%)$. The number of environmental emergencies is still large, but the proportion of reasonable treatment stays at a low level.

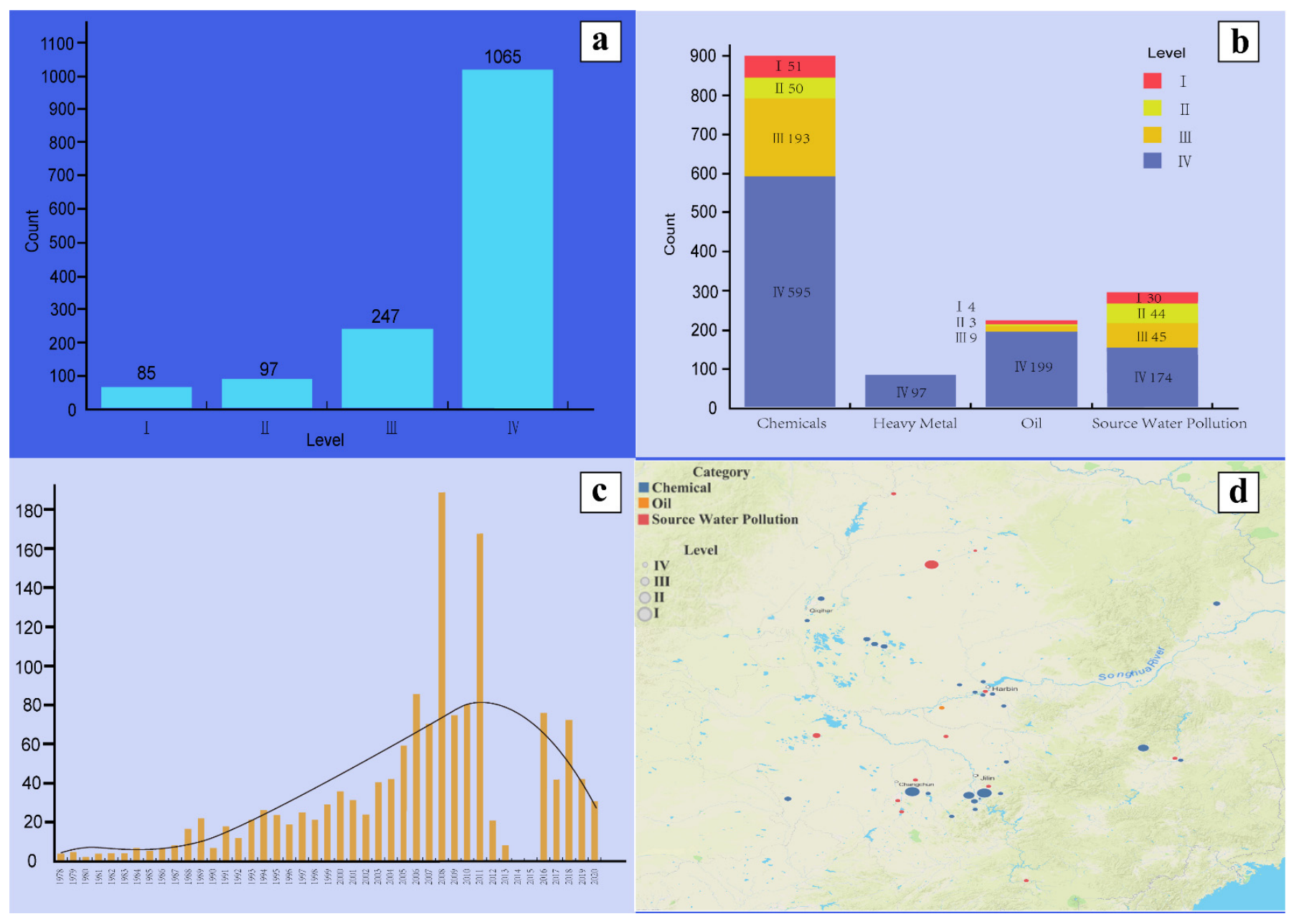

Figure 1. Water pollution accidents in China. (a) Source types, and the level of each type. (b) Spatial distribution of pollution accidents. (c) The number of accidents that happened each year and estimated trend. (d) The serious level of water pollution accidents.

The environmental emergency accident is a complex system and usually causes secondary pollution. Many studies are trying to establish or optimize emergency response systems to reduce risks and negative impacts of sudden water pollution accidents.

\subsection{Previous Studies on Environmental Emergency Response}

When water pollution emergency incidents happen, classification and identification are firstly needed to recognize and predict the risk and the most vulnerable objects accurately and support the next step's movement. Many researchers have work on this subject. For example, a groundwater risk source identification model was constructed based on the comprehensive analysis of contaminant source structure and the evaluation of the contaminant transport process [1]. In addition, Hu et al. [2] constructed a dynamic model 
based on uncertainty analysis and risk assessment for sudden water pollution accidents. To recognize the most sensitive sections of a river, $\mathrm{Li}$ [3] calculated the general risk scores based on the environmental water quality standard and the health risk using the fuzzy logic method. Penman et al. [4] used a Bayesian decision network modeling to manage environmental risk.

After the risk assessment, proper emergency response techniques should be chosen according to the pollutant type and should be customized by many factors such as the density of pollutants and the solubility of pollutants. To find the proper emergency treatment technologies, Zhang and Chen [5] tested the technological efficiency of about 100 contaminants. To address the reason for source water contamination accidents in China, Zhang et al. [6] discussed the origins of typical cases of contamination as well as the emergency response to these accidents and found the main reasons are the excessive pursuit of rapid industrialization and the unreasonable location of factories. With the sudden water pollution accident being a dynamic process, some scholars divided the technique evaluation system into several parts. Shi et al. [7] built an emergency disposal technique index system made up of four parts: the control of pollution source, anti-proliferation of pollutants, the removal of pollutants, and the disposal of used emergency materials.

\subsection{Emergency Response Framework in China and Other Countries}

In terms of emergency response frameworks, many countries have performed better than China. The environmental emergency response system of UNEP/OCHA Joint Environment Unit (JEU) is mainly made up of three parts [8]: rapid environmental assessments using the Flash Environmental Assessment Tool [9] to analyze the risks to human health and ecosystems of a sudden disaster, sampling and analysis of air, water, soil, hazardous, and toxic substances to provide immediate expert recommendations for appropriate followup action and deployment of technical experts within $48 \mathrm{~h}$ of an emergency to carry out detailed assessments over two to three weeks. In the disaster of hurricane Dorian, the system showed great decision support ability [10].

The development of each module of China's emergency response system is basically finished. Compared with other countries in the world, it lacks an overall system for emergency response. Since the Songhua River water pollution incident in 2005, China has basically established a risk analysis, control, and emergency management system for environmental emergencies [11]. Relevant laws, regulations, standards, and norms have been gradually established and the environmental emergency response capability has been continuously improving. Several major sensitive environmental emergencies have been properly handled: in response to the 8.12 chemical explosion accident in Tianjin Port in 2015, the Bohai Sea was successfully prevented from being polluted by sewage that contains cyanogen [12]. In the leakage accident of Luming Mining tailings pond on 28 March 2020, in Yichun, Heilongjiang, the leakage of sewage into the Songhua River was successfully prevented [13]. However, because of the unchanged industrial structure and of heavy chemicals and energy structure dominated by coal, China is still under great pressure from sudden water pollution accidents.

\subsection{Brain-Inspired Studies}

Sudden water pollution accident is a dynamic iterative process of real-time evolution, while the current framework cannot follow up according to the change of pollution situation and provide decision support. Some researchers have explained the dynamic evolution process [14] but did not provide solutions.

Facing the real-time change of environmental accidents, the human brain's great adaptive ability and robustness helps a lot with dealing with those kinds of emergency events. However, decisions made by people under great pressure are distorted [15]. Therefore, a decision-making framework that can achieve the adaptability and robustness of the human brain without the distortion of pressure would be of great benefit to the response to sudden water pollution. 
The characteristics of the human brain have also inspired many studies such as [16-18]. The framework of this study is also based on the brain-inspired structure. Specifically, there are two cognitive systems in the human brain for decision-making: the rapid, spontaneous, unconscious cognitive process and the slow, deliberate, and conscious cognitive process [19]. In the face of a complex and urgent emergency water pollution event, this ability to give a quick response initially and further give detailed logical reasoning information to follow up the development of the event at any time is greatly conducive to emergency decision support.

Our study of a brain-inspired dynamic emergency response framework is made up of the following parts:

Firstly, the fast cognitive process of the human brain is simulated using KNN to match approximate cases in the past, and then, the careful reasoning process of the human brain is simulated by dynamic programming. At the same time, an iterative approach is adopted in the reasoning process to achieve the ability that the human brain can interact with the environment in real-time and respond according to the development of the situation.

This type of brain-inspired system is compatible with the fast response and logical accuracy advantages, but also overcome the disadvantages of the inaccuracy of one-off matches, lack of previous cases, and the long time-consuming reasoning. As the water pollution event being an iterative process, many measures need to be repeatedly evaluated after implementation, and a new scheme should be given under the current conditions. Only by responding flexibly to the current situation can the framework provide effective assistance throughout the process.

\section{Mechanism of Our Brain-Inspired Multi-Stage Dynamic Environmental Emergency Response System}

\subsection{Study Area}

To verify the practicability of the response framework, a major water pollution event, the leakage event of the tailings pond of the Luming Mining Industry in Yichun on 28 March 2020, was selected to test our framework. The study area is shown in Figure

2. The whole process can be divided into two parts: fast case matching and dynamic iterative reasoning.

The 28 March tailings pond leakage accident of Yichun Luming Mining Company is the largest tailings leakage in China in the past 20 years. It requires elaborative emergency treatment, and the task of ecological environment restoration was extremely arduous. At 13:40 on 28 March, the overflow well No. 4 of molybdenum tailings pond in Yichun Luming Mining Co., Ltd. (located in Yichun, China). tilted, resulting in increased discharge accompanied by tailing sand. About 2.53 million cubic meters of sewage with tailings leaked into the Yijimi River about $3 \mathrm{~km}$ after it flowed out. As a result, the water of the Yijimi River was polluted, and the water quality of the Hulan River in downstream was threatened. The Hulan River flows into Songhua River, which is one of the largest rivers in China.

Set reducing pollution load and mitigate the disturbance of the accident to the society to the minimum as the goal, "do not let polluted water get into the Songhua River", the emergency response schedule is carried out. 


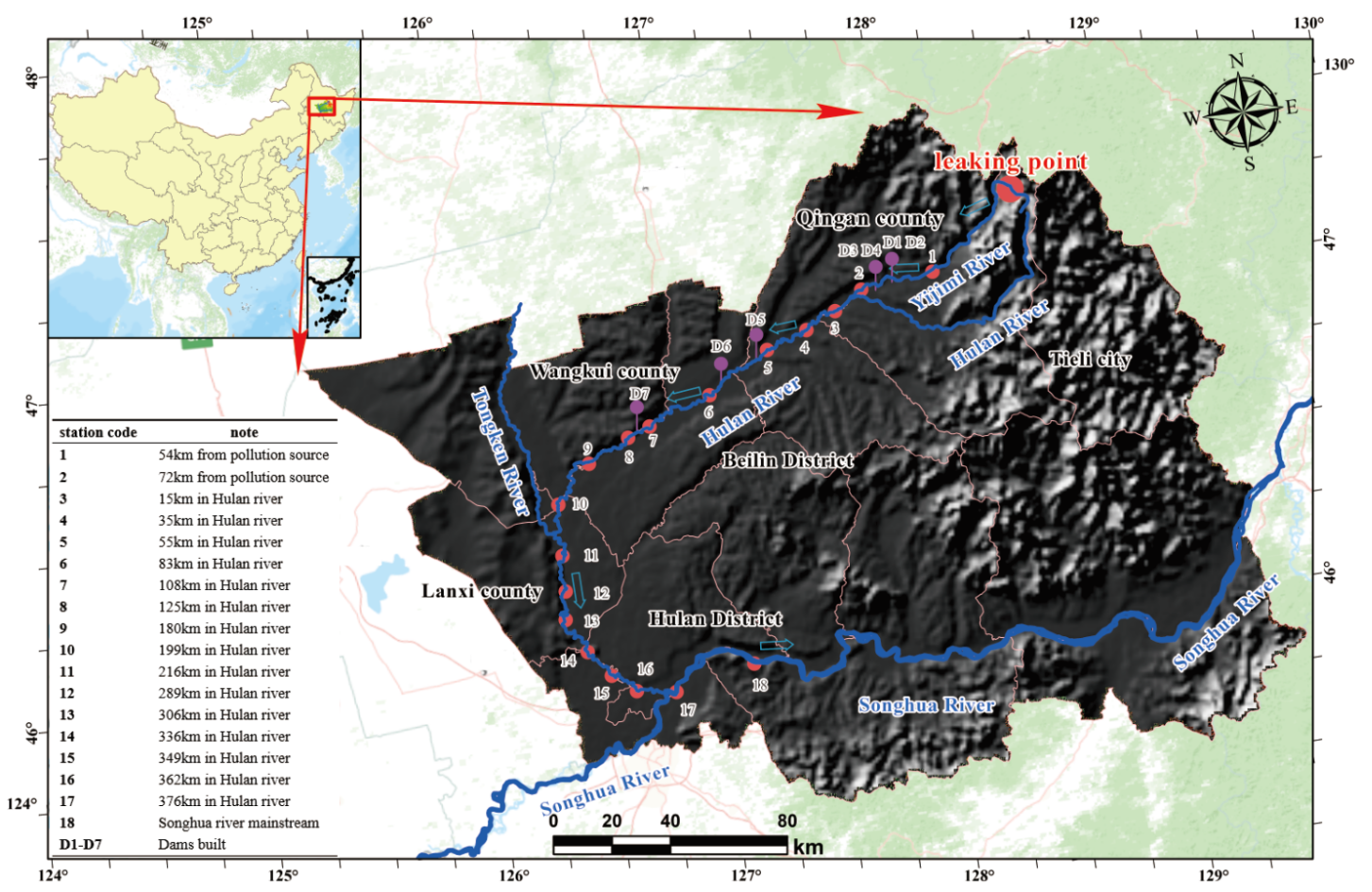

Figure 2. The study area of Yichun Luming.

\subsection{Basic Architecture of the Brain-Inspired System}

Evans [19] first brought out the idea that there are two cognitive systems in the human brain for decision making: the rapid, spontaneous, unconscious cognitive process and the slow, deliberate, and conscious cognitive process are completely different. Except for the human brain, no other natural or artificial system can adapt to new environments and challenges, automatically acquire new information and skills, make effective decisions in complex environments, and work steadily for decades like human brains. No system can maintain as robust as the human brain under the condition of multiple injuries, and no artificial system can match the low energy consumption of the human brain when handling complex tasks [20]. In facing a complex and urgent emergency water pollution event, this ability to give a quick response initially and further give detailed information for logical reasoning is greatly conducive to emergency decision support. The brain-inspired decision support system is inspired by the cognitive behavior mechanism. Its goal is to enable machines to realize various cognitive abilities and synergistic mechanisms of human beings in a brain-like way and finally reach or surpass the level of human intelligence.

The dual-process theory of the human decision-making process inspired the design of our environmental emergency system (Figure 3): Firstly, the rapid cognitive process of the human brain is simulated by KNN fast matching of past approximate cases, and then, the careful reasoning process of the human brain is simulated by dynamic programming. At the same time, the iterative method is adopted in the process to simulate the nature in which the human brain can interact with the environment in real-time and respond according to the development of the situation. This brain-inspired system combines the advantages of rapid response and accuracy of reasoning and also overcomes the shortcomings of inaccurate one-off matches, lack of cases, and long reasoning time. The most important thing is that pollution incidents are in a process of development, and many measures need to be repeatedly evaluated after implementation to provide an adjusted plan under the current situation again. Only by responding flexibly to the current situation can effective assistance be provided throughout the process. Therefore, this method can be applied to the generation of the emergency plan with promptness and accuracy after the occurrence of an emergency. 


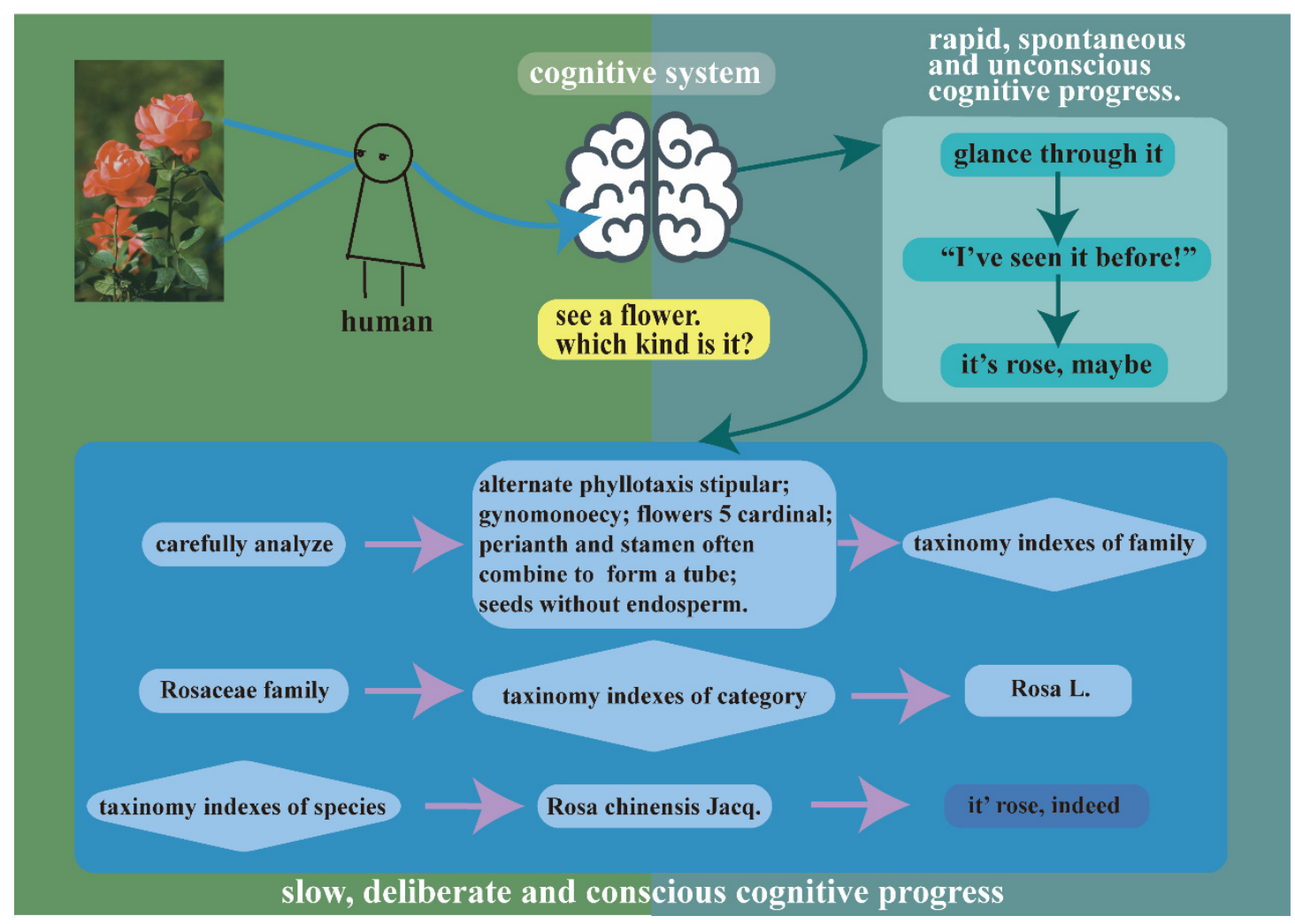

Figure 3. Human cognitive system operation when recognizing flower.

\subsection{Multi-Stage Theory of Emergency Response to Sudden Water Pollution}

After the occurrence of a sudden water pollution accident, the evolution of the situation is a dynamic process. Throughout the process, the state of the event evolves with the emergency response measures taken at each step. That is, the state of each step builds on the state transition of the previous step. How to conduct dynamic planning and modeling for sudden water pollution events, reasonably divide the stages, and make the most appropriate response at the current stage under the current state are important problems of the environmental emergency decision support system. For the source control stage, the leakage of the source should be immediately stopped while preventing the increase in leakage caused by inappropriate source control methods. For anti-proliferation, different anti-proliferation measures should be chosen according to the situation. For the contaminant elimination, considering the river water conditions, method selection and engineering facilities, or problems such as low treatment efficiency or inability to carry out measures, measures need to be modified in time. Attention should be paid to the safety of disposal measures to avoid secondary pollution of rivers or soil in the process of emergency waste disposal.

We divide the treatment and disposal technology schemes into four stages: pollution source control, anti-proliferation, contaminant elimination, and waste disposal. At each stage, decisionmakers are required to make decisions about processing technologies according to selection indexes. For example, in the pollution source control stage, the decisionmaker needs to choose the control technology method according to the pollutant type, the pollutant medium, and the state of existence, and the quantity and concentration of the pollutant. In the anti-proliferation stage, the current pollution situation should be analyzed according to the state of pollution source control measures after implementation, and the measures should be selected according to the concentration of pollutants and the diffusion state. In the next stage of contaminant elimination, measures should be selected according to the concentration, quantity, and nature of pollutants under the influence of anti-proliferation measures. In the final stage of waste disposal, waste produced in 
the emergency treatment process of the previous three stages needs to be disposed of according to the type and quantity. It can be seen from above that the decisions of each of the four stages are based on the influence of the decisions of the previous stage; that is to say, the entire pollutant treatment process is an iterative dynamic planning process. Therefore, throughout the four stages, the idea of dynamic programming and combinatorial optimization methods should be used to give the most appropriate emergency response measures at each stage of the dynamic process. It should be noted that in the process of state transfer, the evaluation index system at each stage does not change. The pollutant status and technical screening evaluation indexes of each stage are shown in Table 1.

Table 1. Evaluation index system of each stage.

\begin{tabular}{|c|c|c|c|}
\hline Source Control & $\begin{array}{c}\text { Pollutant } \\
\text { Anti-Proliferation }\end{array}$ & $\begin{array}{l}\text { Contaminant } \\
\text { Elimination }\end{array}$ & Waste Disposal \\
\hline Type of pollutant & Type of pollutant & Type of pollutant & Type of waste \\
\hline Pollution medium & Pollution medium & Pollution medium & Quantity of waste \\
\hline Existential state & Existential state & Existential state & Cost of treatment \\
\hline Sensitive receiver & Sensitive receiver & Sensitive receiver & Protection \\
\hline Pollution time & Flow velocity & Materials & \\
\hline Location & Quantity of flow & Environment & \\
\hline Toxicity & $\begin{array}{l}\text { Location of } \\
\text { contamination cluster }\end{array}$ & Available place & \\
\hline Weather & $\begin{array}{l}\text { Quantity of pollution } \\
\text { cluster }\end{array}$ & Weather & \\
\hline Damaged container & Area flows through & & \\
\hline Measures can be taken & Measures can be taken & & \\
\hline
\end{tabular}

\subsection{Fast Matching Method of Previous Cases}

The fast matching method based on KNN and R-AHP is used to simulate the fast response process of the human brain. The $\mathrm{KNN}$ algorithm is chosen because it is the most recognized case-matching machine learning algorithm at present [21]. Each stage is matched respectively according to the four stages divided above. By retrieving the case that is most similar to the current case in the database, the reference of the target case is given. Because this part of our system is similar to the case-based reasoning method, the measurement of similarity between cases is of great importance. The measurement of similarity between cases is calculated according to the case attributes, and different methods are used to calculate the similarity for different attribute types. To ensure the speed of the matching process, the nearest neighbor function calculation method was used to perform direct matching without training in advance.

The matching theory of the KNN method states as follows: there is a sample data set, also known as the training sample set, and each datum in the sample set has a tag; after inputting the new data without a solution, each feature of the new data is compared with the feature corresponding to the data in the sample set, and then the algorithm extracts the most similar data in the sample (the nearest neighbor). Generally, only the top $k$ most similar data in the sample data set were selected, where $k$ is usually an integer smaller than 20.

The formula of the nearest neighbor function is as follows:

$$
E\left(s_{0}(k), s_{j}(k), W\right)=\frac{\sum_{k=1}^{n} \omega_{k} \times \operatorname{sim}\left(s_{0}(k), s_{j}(k)\right)}{\sum_{k=1}^{n} \omega_{k}}
$$

where $s_{0}(k)$ is the $k$-th index of the input target case, $s_{j}(k)$ is the $k$-th index of the $j$-th case in the database, $\omega_{k}$ is the measure of the importance of the $k$-th index, and $\operatorname{sim}\left(s_{0}(k), s_{j}(k)\right)$ is the function to measure the similarity between the target case and the $j$-th case in the database. 
Attributes can be divided into continuous value type, discrete numerical type, and determined symbol attribute value type. When the $k$-th index is of continuous numerical type,

$$
\operatorname{sim}_{k}=1-\left[s_{0}(k)-s_{i}(k)\right] / \operatorname{range}(s(k))
$$

where range $(s(k))$ is the value range of the $k$-th index. When the $k$-th index is of discrete numerical type,

$$
\begin{aligned}
& s_{0}(k)=s_{j}(k), \operatorname{sim}_{k}=1 \\
& s_{0}(k) \neq s_{j}(k), \operatorname{sim}_{k}=0
\end{aligned}
$$

When the $k$-th index is determined symbol attribute value type,

$$
\begin{aligned}
& s_{0}(k)=s_{j}(k), \operatorname{sim}_{k}=1 \\
& s_{0}(k) \neq s_{j}(k), \operatorname{sim}_{k}=0
\end{aligned}
$$

The weight of the index was determined by the R-AHP method. AHP is a kind of multi-index comprehensive evaluation method, including the construction of a low-level structure, the establishment of a judgment matrix, the calculation of index weight value, the consistency test, and other operational processes. To simplify the process and respond quickly, the three-scale method was used to establish the comparison matrix.

First, build the comparison matrix. When establishing the comparison matrix $\mathrm{A}$, if a row attribute is considered more important than a column attribute, the matrix element $A_{i j}$ is set to 2 ; if they are equally important, $A_{i j}$ is set to 1 ; if a row attribute is less important than a column attribute, $A_{i j}$ is set to 0 .

Then, build the judgment matrix $B$. Calculate the importance ranking index $r_{i}=\sum_{i=1}^{k} A_{i}$, $r_{\max }=\max \left\{r_{i}\right\}, r_{\min }=\min \left\{r_{i}\right\}$, the element $B_{i j}$ in matrix $B$ is expressed as follows:

$$
B_{i j}=\left\{\begin{array}{l}
\frac{r_{i}-r_{j}}{r_{\max }-r_{\min }}\left(k_{m}-1\right)+1, r_{i} \geq r_{j} \\
{\left[\frac{r_{j}-r_{i}}{r_{\max }-r_{\min }}\left(k_{m}-1\right)+1\right]^{-1}, r_{i}<r_{j}}
\end{array}\right\}, \text { where } k_{m}=\frac{r_{\max }}{r_{\min }}
$$

Calculate the transfer matrix of the judgment matrix

$$
C_{i j}=\lg B_{i j},(i, j=1,2, \cdots, n)
$$

According to the transfer matrix, calculate the optimal transfer matrix

$$
D_{i j}=\frac{1}{n} \sum_{k=1}^{n}\left(C_{i k}-C_{j k}\right)
$$

Then, the quasi-optimal uniform matrix

$$
B_{i j}{ }^{\prime}=10 D_{i j}
$$

\subsection{Iterative Generation Scheme of Dynamic Programming Reasoning}

Emergency response to sudden water pollution is a multi-stage decision-making problem, which requires dynamic programming ideology. The idea of dynamic programming can be explained as a basic state transfer relation, through which the multi-stage decisionmaking problem is transformed into multiple single-stage decision-making problems. By solving each single-stage decision-making problem, the whole problem-solving process becomes clear and simple and easier to realize. In addition, the decisions available at each stage are not arbitrary. They depend on the state of the decision and how they affect it. When decisions are made at all stages, a sequence is formed, and the final state of the sequence determines the final course of the subsequent decision-making process. 
Regard the emergency response process of sudden water pollution accident as the following combinatorial optimization problem:

$$
\begin{gathered}
\text { minimize } C(a) \\
\text { subject to } a \in A
\end{gathered}
$$

where $A$ is the feasible domain of the solution and $C(a)$ is the objective function. Assuming that each solution in $A$ has $N$ units, corresponding to $N$ emergency response phases, so one solution $a$ in $A$ can be expressed as $a=\left(a_{1}, \ldots, a_{N}\right)$.

For an optimization problem of emergency response to sudden water pollution accidents, regard it as the form of a dynamic programming question with $\mathrm{N}$ stages. For the stage $t$ in this question, the decision variable at this stage is all feasible $\left(a_{1}, \ldots, a_{t}\right)$ solutions. Assume that the original state is $a_{0}$; therefore, the feasible domain $A_{1}$ of $a_{1}$ can be stated as:

$$
A_{1}=\left\{\widetilde{a}_{1} \mid \exists\left(\widetilde{a}_{1}, \widetilde{a}_{2}, \ldots, \widetilde{a}_{N}\right) \in A\right\}
$$

Similarly, after the stage $t$ finished, given $\left(a_{1}, \ldots, a_{t}\right)$, the next stage's decision $\left(a_{1}, \ldots, a_{t}, a_{t+1}\right)$ should satisfy that $a_{t+1}$ stays in the following feasible domain:

$$
A_{t+1}\left(a_{1}, \ldots, a_{t}\right)=\left\{\widetilde{a}_{t+1} \mid \exists\left(a_{1}, \ldots, a_{t}, \widetilde{a}_{t+1}, \ldots, \widetilde{a}_{N}\right) \in A\right\}
$$

The final stage generates a termination penalty $C(a)$, where $a=\left(a_{1}, \ldots, a_{N}\right) \in A$. Note that no penalty should be generated in any other stages.

Thus, the recursive formula of the dynamic planning process for emergency response of sudden water pollution accident is obtained as follows:

$$
\begin{aligned}
\forall t=1, \ldots, N-1: V_{t}^{*}\left(a_{1}, \ldots, a_{t}\right)= & \min _{a_{t+1} \in A_{t+1}\left(a_{1}, \ldots, a_{t}\right)} V_{t+1}^{*}\left(a_{1}, \ldots, a_{t}, a_{t+1}\right) \\
& \left(\operatorname{def} V_{N}^{*}\left(a_{1}, \ldots, a_{N}\right)=C\left(a_{1}, \ldots, a_{N}\right)\right)
\end{aligned}
$$

\section{Building the Environmental Emergency Response System}

After the occurrence of a water pollution event, the basic information of the current event is firstly collected, and then a fast-matching search is conducted according to the corresponding indexes in Table 1 to provide the case base with similar pollution events that have happened in history to provide a preliminary reference for decision making.

Then, the dynamic programming iterative reasoning process should be performed. Each step is inferred through dynamic programming, and the feasible domain is the available technical method limited by each evaluation index in the current stage. It is important to note that since the emergency response process is not a one-step process, it needs to be adjusted according to the development of the event, and the stages do not advance linearly over time. At any time when the decisionmaker needs decision support and at the beginning of each stage, the algorithm needs to evaluate the current situation, judge whether to execute the operation of one or several stages in the four stages, and generate feasible solutions by reasoning.

The Figure 4 shows the evolution process over time and the flow of emergency response measures. Figure $4 \mathrm{a}$ is the schematic diagram of multi-factor co-evolution. In this figure, $a_{1}, \ldots, a_{N}, b_{1}, \ldots, b_{N}, c_{1}, \ldots, c_{N}, d_{1}, \ldots, d_{N}$ are the indicators of each layer, and the arrows represent the evolution caused by the operation of emergency measures. Note that there are not only four phases, but $\mathrm{n}$ possible phases, because decisionmakers may be able to redo one of these phases over time or when the pollution state changes. Figure $4 \mathrm{~b}$ is the description of the process of our sudden water pollution accident response system. 


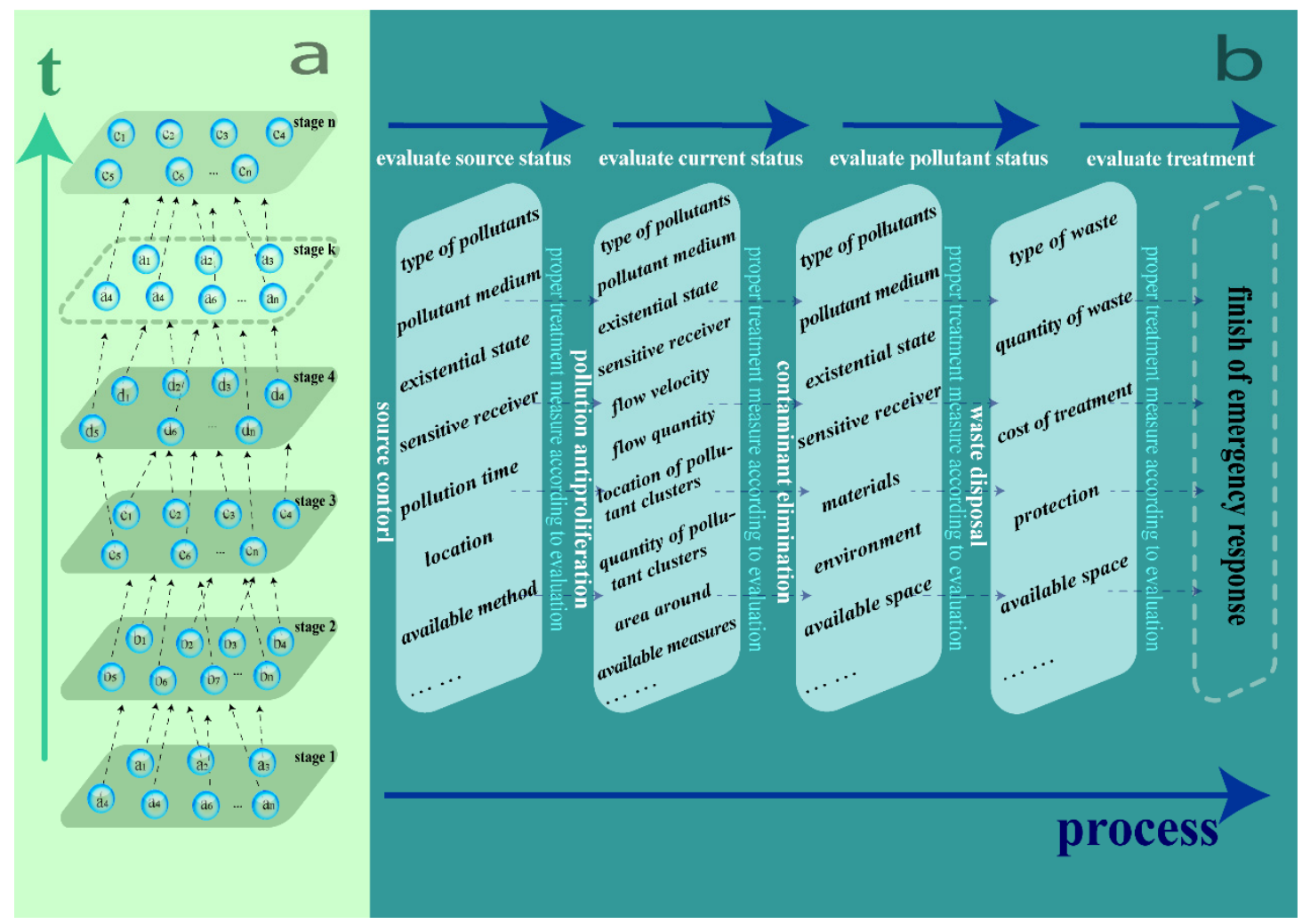

Figure 4. Evolution process over time (a) and the flow of emergency response measures (b).

An auxiliary determination index system for each stage is established to provide a reference for determining whether the target of this stage is accomplished or not, and whether it is necessary to carry out emergency response measures for this stage. Focusing on the reduction of pollutant concentration as the target, the system is divided into the starting index and iteration/ending index. For each stage, the two tables work together to determine the methods. Table 2 is the judgment assist index system for the start of each stage. The first column is fixed evaluation criteria, and the last two columns are filled in according to the situation to assist decision making. Table 3 is the standard for the change and termination judgment assist index system of each module in operation. While the emergency response procedure is running, we need to check the standards in the table according to the actual situation to decide whether to iterate or terminate a module.

Table 2. Judgment assist index system for the start of each stage.

\begin{tabular}{ccc}
\hline Judgment Indicators & Corresponding Data & Explanation \\
\hline $\begin{array}{c}\text { time difference between the occurrence and } \\
\text { current time and event } \\
\text { the current pollution scope and } \\
\text { development state } \\
\text { pollution severity }\end{array}$ & $\begin{array}{c}\text { input data here based } \\
\text { on the situation }\end{array}$ & $\begin{array}{c}\text { input data here based } \\
\text { on the situation }\end{array}$ \\
current pollution source leakage state \\
concentration \\
state of proliferation \\
if waste disposal is needed \\
modules can be chosen
\end{tabular}


Table 3. Judgment assist index system for iteration and ending of each stage.

\begin{tabular}{|c|c|c|c|c|}
\hline & Source Control & $\begin{array}{c}\text { Pollutant } \\
\text { Anti-Proliferation }\end{array}$ & Contaminant Elimination & Waste Disposal \\
\hline starting criteria & $\begin{array}{l}\text { Judged by decision } \\
\text { module (start) }\end{array}$ & $\begin{array}{l}\text { Judged by decision } \\
\text { module (start) }\end{array}$ & $\begin{array}{l}\text { Judged by decision module } \\
\text { (start) }\end{array}$ & $\begin{array}{l}\text { Judged by decision } \\
\text { module (start) }\end{array}$ \\
\hline iteration criteria & $\begin{array}{l}\text { the traffic condition } \\
\text { the engineering } \\
\text { parameters of dams } \\
\text { ecological risks of } \\
\text { sensitive receptors }\end{array}$ & $\begin{array}{l}\text { the flow rates of inflow } \\
\text { and outflow rivers } \\
\text { the traffic condition } \\
\text { flow velocity and } \\
\text { quantity } \\
\text { ecological risks of } \\
\text { sensitive receptors }\end{array}$ & $\begin{array}{c}\text { reduction of pollutant } \\
\text { concentration } \\
\text { if there are sufficient medicals } \\
\text { the flow rates of inflow and } \\
\text { outflow rivers } \\
\text { flow velocity and quantity } \\
\text { ecological risks of sensitive } \\
\text { receptors }\end{array}$ & $\begin{array}{l}\text { Sufficient engineering } \\
\text { facilities }\end{array}$ \\
\hline ending criteria & $\begin{array}{l}\text { source does not } \\
\text { continue to leak } \\
\text { the leakage amount is } \\
\text { small }\end{array}$ & $\begin{array}{l}\text { anti-proliferation work } \\
\text { completed } \\
\text { pollutant concentration } \\
\text { reach the standard }\end{array}$ & $\begin{array}{l}\text { pollutant concentration reach } \\
\text { the standard }\end{array}$ & $\begin{array}{l}\text { waste properly } \\
\text { disposed }\end{array}$ \\
\hline
\end{tabular}

According to the event information and the judgment index, first determine which parts of the task need to be executed. At the beginning of the emergency response, the main problem is often that the decisionmaker does not know which phases or works should be parallel and which should be serial, resulting in wasted resources and time. The index system of each stage is screened according to the technology in Table 1, and the applicable technology under the current situation is inferred from the technology database. The technology library used in this study is from the emergency technology library of School of Environment, Harbin Institute of Technology. After the completion of tasks in each stage, the experts should determine whether operations need to be performed again in this stage according to the effect. At the same time, throughout the emergency response process, experts can decide to change plans at any time as the pollution event evolves, reassessing which phases should be implemented based on the current situation. The whole response process is accompanied by the deployment of people, money, and materials and the flow of information.

When the implementation of source control, non-proliferation, and pollutant elimination is completed and no further operation is required, according to the situation of waste generated in the process of treatment and the technical index system of waste treatment, an emergency material waste disposal plan must be generated. After the emergency waste treatment measures are completed, a global judgment is made to determine whether the short-term and long-term goals of reducing pollutant concentration, protecting human and ecological environment health, and not having a long-term impact on the environment have been achieved in all stages.

\section{Case Study}

\subsection{Fast Matching of Historical Event}

\subsubsection{Using the AHP Method to Determine Factor Weights}

When a person first learns about an emergency, it is common for humans to search for similar cases in the past and think about what has been done and then maybe that could have been applied to the present situation. To simulate the rapid cognitive function of the human brain, the machine learning method KNN is used to match historical cases as human memory and give top historical cases with the highest correlation with our target case and their corresponding methods. First of all, to ensure the closeness of situations can be calculated in the feature spaces, the AHP method [22] is used to determine the weight of the index. Here are the suggested weights based on past processing experiences, 
which users can adjust flexibly according to their perception. In total, 14 indicators that we consider important are selected, and the comparison matrix by the 1-9 scale method is defined. The relative importance of factors is shown in Table S1. The calculated weights are shown in Table S2. The characteristic value was chosen as the weights; then, normalization was performed.

\subsubsection{Numerate the Indexes}

After the weight of the index is determined, the indexes needs to be numerated. There are three types of indexes: numerical, symbolic, and fuzzy. The attribute-dividing result is shown in Table S3.

For fuzzy and symbolic indexes, the criteria for numeration are shown in Table S4. The numeration results of the events and corresponding indexes are shown in Table S5. See SI for details of the events corresponding to each number.

\subsubsection{KNN with Weights}

After the index is numerated, the KNN algorithm can be used for matching. The KNN algorithm gives the approximate degree of each event and the target event according to the position of each event in the feature space. The closer the distance in the feature space, the more similar the event is to the target.

Similarity, according to Euclidean distance, is shown in Table S6. The calculation results showed that E14, E1, E12, and E13 have high relevance with the target event; therefore, the processing methods of corresponding events were chosen as a reference.

Based on the matching event, decisionmakers can obtain some references for how to handle it (shown in Table 4). This gives the emergency manager a sense of security, making them less nervous. However, there are limits to this rapid initial learning. Since people may not recall anything or can only remember some fragments of past events. Our matching, too, is likely to encounter similar problems. Due to the failure of information recording, or maybe to there being few cases like this before, it is hard to match similar historical cases. Just as humans cannot live with half of their brains, decisionmakers need to carry out the next part, which is a robust dynamic iterative reasoning system.

Table 4. Treatment measures of corresponding events.

\begin{tabular}{ccccc}
\hline Event & Treatment Measures & Adsorption & Secure landfill \\
E14 & Leaking stoppage & $\begin{array}{c}\text { Construction } \\
\text { dam } \\
\text { Activated } \\
\text { carbon } \\
\text { adsorption }\end{array}$ & $\begin{array}{c}\text { Coprecipitation } \\
\text { method }\end{array}$ & \\
E12 & $\begin{array}{c}\text { Closure of pollutant } \\
\text { discharge } \\
\text { Clischarge }\end{array}$ & Adsorption & \\
E13 & Dig trenches & Covering/adsorption & $\begin{array}{c}\text { Municipal } \\
\text { wastewater } \\
\text { treatment }\end{array}$ \\
\hline
\end{tabular}

\subsection{Dynamic Programming Iteration Process of the Whole Event}

Event occurrence: 28 March, 13:40, The overflow well No. 4 of the molybdenum mine tailings pond of Yichun Luming Mining Co., Ltd. tilted, resulting in increased discharge and tailing sand leakage. The sewage with tailing sand was about 2.53 million cubic meters, and the sewage flowed into the Yijimi River about $3 \mathrm{~km}$ later. The concentration was very high (turbidity over 10,000 NTU) in the river, if we left the pollutant unsolved, it would greatly endanger the safety of downstream water. In addition, we need to retard the proliferation to give enough time for the treatment.

Stage 1: Preceptors + decision module 
At this stage, we need to decide the modules that need to be carried out. Preceptors need to obtain basic information related to contamination events for system determination. Indicators needed by the system for judgment and corresponding data obtained by preceptors under the current state are shown in Table S7 (stage 1).

According to the decision module, we can choose the emergency response plan of source control and anti-proliferation at this stage. This means the operation of source control and anti-proliferation phase need to be carried out simultaneously.

Then, we need to decide the methods for each module using the on-site data and the evaluation indexes of the two modules. The evaluation indexes aim to help us to identify the types and quantities of pollutants, the leakage amount, sensitive receptors that we need to protect the downstream, and whether there are supporting machinery and structures for carrying out the plan. By performing this evaluation, we can check out the situation thoroughly and give the optimal treatment under careful consideration for the current situation, thus minimizing possible failure caused by human decision-making oversight. Evaluation index and corresponding data of the current stage are shown in Table S7 (stage 1).

Data was obtained from on-site monitoring stations at that time. The feasible region of techniques corresponding to the above indexes is shown in Table S7 (stage 1).

After generating the feasible techniques list, we supplemented it with expert evaluation. In the source control operation, the methods of leaking stoppage and construct dams were adopted, building 10 dams in the downstream Yijimi River to slow the flow rate and increase the reaction time. We used flocculant and activated carbon to adsorb and flocculently precipitate the pollutants, preventing the downstream migration of pollutants. See Figure S1 for the picture of the high concentration of Molybdenum in the river.

Stage 2: Iteration of source control + anti-proliferation

After the operation of stage 1, the system still remains for further refinement work. During the whole process, we needed to judge if some stages should have several iterations. The main criteria for deciding whether to change the status or implement new measures are shown in Table S7 (stage 2).

On 28 March, there was no road access for $2 \mathrm{~km}$ leading to the No. 4 overflow well. In addition, due to the limitation of climatic conditions during the spring thaw period, large machinery could not reach the site of No. 4 overflow well, and source control could not be implemented.

Due to the constraint of "the traffic condition" judgment index, we needed to modify the current measures of source control, place the focus on transportation. The construction of $2 \mathrm{~km}$ of mountain road was completed at $12 \mathrm{o}^{\prime}$ clock on 29 March. This is the first iteration, performed in the source control module.

At 4 a.m. on 30 March, $720 \mathrm{~m}^{2}$ of plugging work was completed, which was close to the leaking point. However, the current situation still cannot meet the finish criteria of the source control module. Under the traffic condition index, we need to expand the working area and conduct dredging operations around the leak site to satisfy the demands for source control and to ensure mechanical access to the No. 4 overflow well. However, because the leakage caused the ice to collapse and buried the leakage point, it is difficult to accurately determine the leakage point at this time. This is the second iteration in the source control module.

At 7 o'clock on the morning of 30 March, the leak point was located, and the ice removal work began. At 14:00, the surrounding area of the leakage point was cleaned up, and the filling material was put into the leakage point of No. 4 overflow well. Due to the complex topography and geological structure of the leakage site, the plugging process was carried out carefully to prevent secondary disasters. At this stage, the leakage point has not been sealed, but the flow rate at the leakage point has decreased significantly.

As the traffic has been solved, we need to double-check the conditions of pollutant anti-proliferation and check the general plan using the decision module once again in the next stage. 
Stage 3: Decision module + iteration of anti-proliferation + start of contaminant elimination

After the measures were implemented in the past stages, the monitoring data are shown in Table S7 (stage 3).

From the table, we can see that the concentration is still high, the front of the pollutant cluster reached the Hulan River Qushou section (110 km downstream of the source), and the peak is at about $77 \mathrm{~km}$ from the source.

According to the analysis of the characteristic pollutant data, there is no sudden change of pollutant concentration in the 10 sections below the estuary of Yijimi River. It is suggested that the upstream damming retarded the diffusion of the pollution cluster, and the pollution cluster was still located above the Hulan River. The measures of pollution source control and anti-proliferation are effective. We need to use the decision module to reconsider our measures in this stage. The judgment indicators and corresponding data of current stage are shown in Table S7 (stage 3).

According to the evaluation index and corresponding data shown in Table S7 (stage 3) and the current pollution state, the focus of work at the current stage should be on "antiproliferation" and "contaminant elimination". For pollutant anti-proliferation measures, as the position of pollutant clusters changed, the location of adding medicals should also be changed. The anti-proliferation project should be implemented on the Yijimi River, and the contaminant elimination project should be implemented on the Hulan River. In addition, due to the fluctuation of flow rate in the thawing period, the flow rate changes should be monitored in real-time, and the dosage should be adjusted according to the current flow rate. The pollutant diffusion state and the measures needed to be taken are shown in Figure S2. The methods adopted and criteria are shown in the Table S7 (stage 3).

Considering the convenience of obtaining economic materials, the flocculation sedimentation method was adopted, and the aluminum polychloride was chosen as the flocculant because it is commonly used in water treatment.

Stage 4: End of source control + iteration of anti-proliferation + iteration of contaminant elimination

While the measures based on the reasoning results of the previous stage were implemented, we monitored the water quality at the accident site and downstream points. At 14:00 on 2 April, molybdenum, chemical oxygen demand (COD), and petroleum in 6 of the 13 monitoring sections exceeded the standard limits, and the other sections were all below the standard limits. Water quality in monitor sites are shown in Table S7 (stage 4).

The front of the pollutant cluster reached the Hulan River Qinaan Bridge section (130 km downstream of the source), and the peak was at about $99 \mathrm{~km}$ from the source. We can see from the table that the concentration of molybdenum decreased, but the effect cannot meet our requirements.

According to the judgment table in Table S7 (stage 4), the source control condition reached the ending criteria, which means the source control module is finished. However, due to the flocculant aluminum polychlorid not being effective, we need to reselect chemicals for sedimentation (Table S7 stage 4).

At this point, the measures can be judged as effective but still cannot meet the criteria for the finish of emergency response; therefore, we continue to perform current measures. The concentration of pollutants in each section is still monitored and prepare for possible problems at any time, to make a dynamic corresponding response plan (Table S7 stage 4).

Stage 5: Start of waste disposal

According to monitoring sites data (Table S7 stage 5), the petroleum and COD of the four sections of the Yijimi River all reach the standard.

Evaluation of the effect of the measures implemented in the previous stages: through the pollutant control on the Yijimi River and the pollutant removal on the Hulan River, the flocculation sedimentation method was adopted to reduce the pollutants in the river effectively. The monitoring data showed that the concentration of pollutants in the Yijimi River 
decreased significantly, and the peak pollution in the Hulan River decreased gradually with the downstream migration of the pollutant cluster.

At present, the detection of molybdenum concentration showed that there is no harm to plants or the human body and it does not affect the groundwater.

Judging from the current situation (Table S7 stage 5), we should start the waste disposal section and clean up the sludge of flocculation and sedimentation. According to the indexes of waste disposal, we should adopt a combination of mechanization and manual removal to comprehensively carry out waste disposal work.

Stage 6: End of pollutant anti-proliferation + iteration of contaminant elimination

After the implementation of the flocculation cleaning project of Hulan River and Suiwang Bridge, the length of the repaired Hulan River reached $200 \mathrm{~km}$, and the pollutants were effectively reduced. At the present stage, according to the site situation and the improvement of water quality, we should further optimize the dosing measures to ensure the effectiveness of the cleaning project. Meanwhile, we should strengthen the water quality monitoring and analysis to provide technical support for accurate pollution control.

As the anti-proliferation work is finished and the concentration of pollutants in the river stays low, this module has satisfied the ending criteria (judgment table shown in Table S7 stage 6). No further actions will be taken on anti-proliferation if there are no sudden changes in the current situation. Modifications are made for contaminant elimination according to the Table S7 stage 6.

Stage 7: End of contaminant elimination + end of waste disposal

After 14 days of emergency response, at 3 o'clock on 11 April, water quality reached the standard at the lower reaches of the Hulan River, about $70 \mathrm{~km}$ from the Songhua River. At 14:00 on 11 April, molybdenum concentrations in 13 monitored sections all met the national standard limit requirements.

Since then, the concentration of the characteristic pollutant molybdenum has consistently reached the standard at all monitoring points along the river basin, and the 275-km stretch of the Hulan River cleared. The water environmental quality of the Songhua River was not affected.

According to the judgment table shown in Table S7 stage 7, at 18:00 on 18 April, the emergency response schedule of Yichun Luming Mining Tailings Pond Leakage was finished.

The judgement during the whole process is shown in Table S7.

\subsection{Results}

After the leakage event occurred, the emergency response mechanism of emergency environmental events was started immediately, the emergency disposal work was carried out comprehensively, the leakage point was sealed in time, the pollution source was cut off, and the safety of the tailings pond was ensured. Based on the successful response to this accident and the previous experience of relevant events, we proposed the brain-inspired emergency response framework in China.

This event is divided into seven stages according to the evolution process (Figure 5). The iteration can be noticed in the following stages specifically: the modification of source control measures due to ice blocking (stage 2); the modification of flocculation sedimentation agents (stage 4); the modification of dosage according to flow change at any time (stage 3-6); and the adjustment of dosage measures according to water quality improvement (stage 6). In this emergency response process, the iterative dynamic programming system runs through the whole solution process. We push forward the stage step by step according to the demand and adjust the thought and method iteratively according to the situation. 


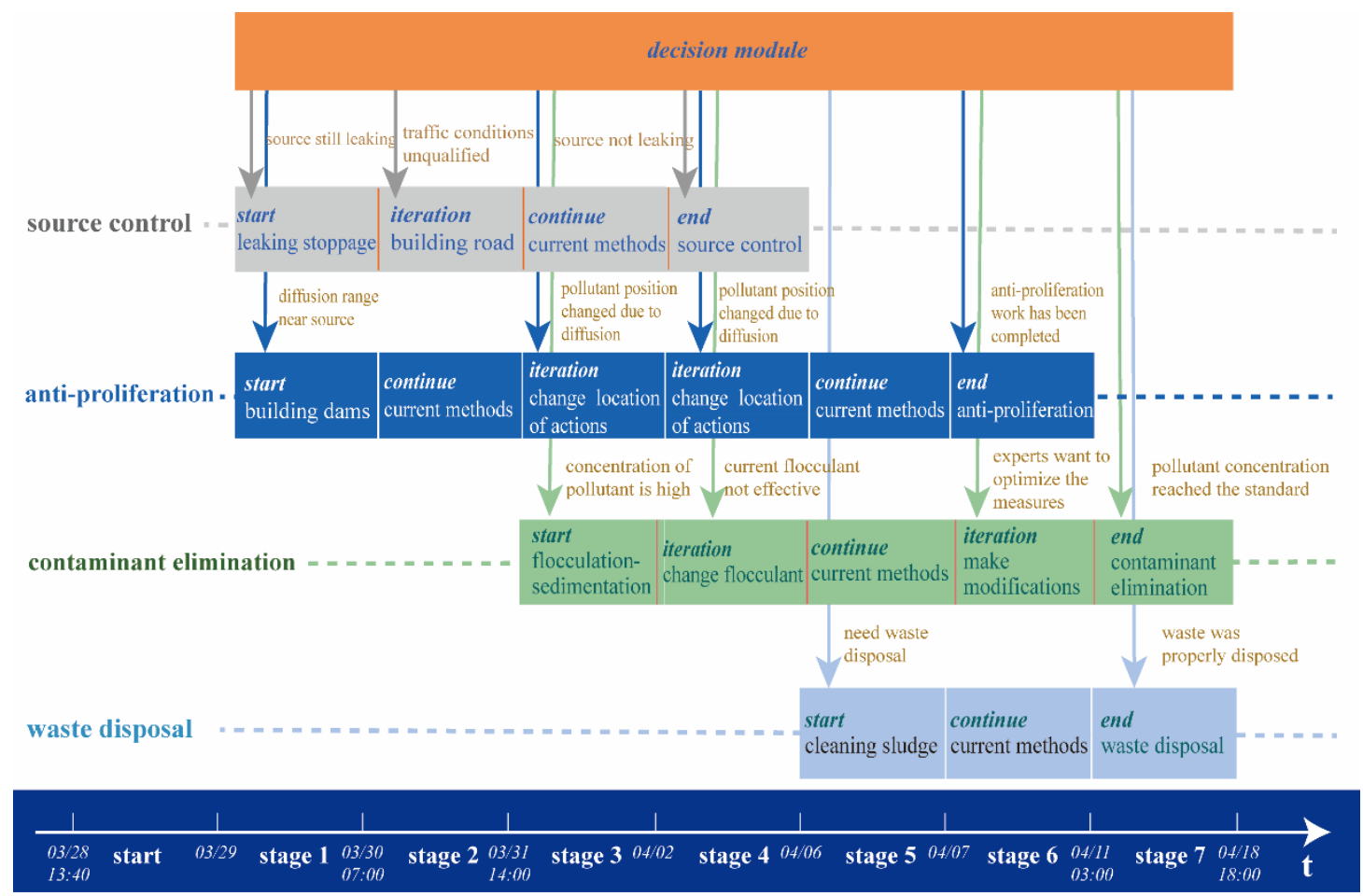

Figure 5. Time process of the event and the actions.

This system is complete and comprehensive and can accompany the whole life of the decision-making process, avoiding the problem of giving a solution then failing to keep up with it. It is a good partner for human decisionmakers.

\section{Conclusions and Suggestions}

Based on the analysis of a large number of historical pollution cases, inspired by the human cognition system, this research attempts to give a comprehensive, full process following the dynamic emergency response framework for sudden water pollution accidents. The robustness and practicability of the framework are tested using actual events of Yichun Luming.

This framework is divided into the following two parts: The first part of rapid cognition is to use the events stored in the library in the past to match through the KNN algorithm to obtain the solution of similar events in history. In the second part, the water pollution treatment and disposal technology schemes are divided into four stages according to the real-time evolution state of the events, and the scheme is improved according to the development state of the events with the idea of dynamic state transition, and the logic and careful reasoning with strong robustness are realized.

Using this framework, we can quickly obtain the historical similar cases' solution after the occurrence of water pollution accidents and give the initial feasible scheme, thus shortening the response time as much as possible, which would help to reduce secondary pollution. Moreover, the existence of such historical similar cases can help emergency decisionmakers to get started quickly, increase the sense of familiarity with the event, and reduce the decision pressure and the possible decision mistakes caused by the pressure. Since the event cannot be implemented by one-time measures, the procedure generally involves many stages, each of which needs to be adjusted according to the actual situation. Our system can follow up the whole stage, imitate the dynamic cognitive and logical reasoning process of human beings, assist in judgment and methodical reasoning for each possible stage and the iterative feedback process that needs to be carried out within each stage, and help decisionmakers to make calm and rational analysis. It is the decisionmaker's second brain, unaffected by stress and always following through. Additionally, this framework 
can also serve to train new decisionmakers to quickly familiarize themselves with the emergency response process, learn from previous work experience, and enter the role of emergency decisionmakers as soon as possible.

Compared with previous studies, this study has the following advantages:

1. Big data analysis based on historical cases of sudden water environmental pollution. This paper innovatively simulates the human brain cognitive system and realizes an emergency response framework that has the thinking advantage of human decisionmakers while not being affected by nervous emotions.

2. For the quick response module, the machine learning method KNN, which does not require pretraining, is used to carry out the fast matching of cases, to optimize the waiting time for model training, and to give possible solutions as quickly as possible.

3. The water pollution incident response module is divided into four stages, and the decision index for each module is given to assist the logical decisions.

4. The most important point, the dynamic iterative process, is implemented in the decision support framework for the first time. This study complements the shortcomings of previous studies that explained the dynamic process but did not provide the corresponding solutions.

There are also some shortcomings in this study, which can be improved in future researches: For the process of dynamic iterative reasoning, to realize the decisionmaker's free judgment on the evolution of events and maximum interaction with environmental changes, the automatic judgment was not realized. The decisionmaker needs to determine the current stage according to the indicators of this framework. In further research, we aim to develop models to simulate and determine the evolution stage and to give all possible evolution states of the event and corresponding solutions fully automatically.

In general, our brain-inspired dynamic environmental emergency response framework has a practical effect on emergency decision-making of sudden water pollution accidents and can be recognized as the second brain of emergency decisionmakers. Historically, the human brain has not been fully exploited and utilized, and the new generation of artificial intelligence technology has just started. Human-machine emergency decision-making still has great development opportunities in the direction of knowledge graphs and so on.

Supplementary Materials: The following are available online at https://www.mdpi.com/article/10 $.3390 /$ w13213097/s1, Figure S1: High concentration of Molybdenum in the river (over 10,000 NTU) (this figure is from the ministry of ecology and environment of the People's Republic of China), Figure S2: Pollutant diffusion state and the measures need to take, Figure S3: Using Polymeric Ferric Sulfate to cut down the contaminant. (this figure is from the ministry of ecology and environment of the People's Republic of China), Table S1: Relative importance of factors, Table S2: Calculated weights, Table S3: Dividing indicator attributes, Table S4: Parameterization standards for each index, Table S5: The numeration results of the events and corresponding indexes, Table S6: Similarity according to Euclidean distance, Table S7: Tables of the dynamic reasoning process.

Author Contributions: Conceptualization, Y.Z. and Y.P.; methodology, Y.P.; validation, Y.Z., Y.P. and L.G.; formal analysis, Y.P.; investigation, Y.P.; resources, L.G.; data curation, W.W.; writing—original draft preparation, Y.P.; writing-review and editing, Y.P.; visualization, Y.P.; supervision, L.G.; project administration, L.G.; funding acquisition, Y.Z. All authors have read and agreed to the published version of the manuscript.

Funding: This research received no external funding.

Institutional Review Board Statement: Not applicable.

Informed Consent Statement: Not applicable.

Conflicts of Interest: The authors declare no conflict of interest. 


\section{References}

1. Jin, A.F.; Li, G.H.; Zhang, X. The Risk Source Identification and Classification Methodology of Groundwater Pollution. Earth Sci. China Univ. Geosci. 2012, 37, 247-252. [CrossRef]

2. $\mathrm{Hu}, \mathrm{M} . ; \mathrm{Qiu}, \mathrm{R} . ; \mathrm{Wu}, \mathrm{D} . ;$ Management, H.S.-T. Undefined Hierarchical Pattern Recognition for Tourism Demand Forecasting; Tourism Management: Amsterdam, The Netherlands, 2021.

3. Li, D.; Shi, L.; Dong, Z.; Liu, J.; Xu, W. Risk analysis of sudden water pollution in a plain river network system based on fuzzy-stochastic methods. Stoch. Environ. Res. Risk Assess. 2019, 33, 359-374. [CrossRef]

4. Penman, T.D.; Cirulis, B.; Marcot, B.G. Bayesian decision network modeling for environmental risk management: A wildfire case study. J. Environ. Manag. 2020, 270, 110735. [CrossRef] [PubMed]

5. Zhang, X.; Chen, C. Emergency drinking water treatment in source water pollution incident-technology and practice in China. Front. Environ. Sci. Eng. China 2009, 3, 364-368. [CrossRef]

6. Zhang, X.J.; Chen, C.; Lin, P.F.; Hou, A.X.; Niu, Z.B.; Wang, J. Emergency drinking water treatment during source water pollution accidents in China: Origin analysis, framework and technologies. Environ. Sci. Technol. 2011, 45, 161-167. [CrossRef] [PubMed]

7. Shi, S.; Cao, J.; Feng, L.; Liang, W.; Zhang, L. Construction of a technique plan repository and evaluation system based on AHP group decision-making for emergency treatment and disposal in chemical pollution accidents. J. Hazard. Mater. 2014, 276, 200-206. [CrossRef] [PubMed]

8. Environmental Emergency Response I UNEP-UN Environment Programme. Available online: https://www.unenvironment. org/explore-topics/disasters-conflicts/what-we-do/preparedness-and-response/environmental-emergency (accessed on 30 December 2020).

9. The Flash Environmental Assessment Tool (FEAT) 2.0-EECentre. Available online: https://www.eecentre.org/resources/feat/ (accessed on 30 December 2020).

10. The Bahamas: Rapid Assessment of Acute Environmental Risks after Hurricane Dorian-EECentre. Available online: https:// www.eecentre.org/2019/11/22/the-bahamas-rapid-assessment-of-acute-environmental-risks-after-hurricane-dorian/ (accessed on 30 December 2020).

11. Lu, X.; Han, Z. Emergency management in China: Towards a comprehensive model? J. Risk Res. 2019, 22, 1425-1442. [CrossRef]

12. Fu, G.; Wang, J.; Yan, M. Anatomy of Tianjin Port fire and explosion: Process and causes. Process Saf. Prog. 2016, 35, 216-220. [CrossRef]

13. Song, S.; Chu, J.; Zhang, H. Study on Environmental Risk Assessment and Control Countermeasures of Tailings pond in a Mountainous Area of North China. IOP Conf. Ser. Earth Environ. Sci. 2020, 585, 012095. [CrossRef]

14. Wang, D.; Wan, K.; Ma, W. Emergency decision-making model of environmental emergencies based on case-based reasoning method. J. Environ. Manag. 2020, 262, 110382. [CrossRef] [PubMed]

15. Kerstholt, J.H. The effect of time pressure on decision-making behaviour in a dynamic task environment. Acta Psychol. (Amst.) 1994, 86, 89-104. [CrossRef]

16. Zhang, Y.; Qu, P.; Ji, Y.; Zhang, W.; Gao, G.; Wang, G.; Song, S.; Li, G.; Chen, W.; Zheng, W.; et al. A system hierarchy for brain-inspired computing. Nature 2020, 586, 378-384. [CrossRef] [PubMed]

17. Zou, Z.; Zhao, R.; Wu, Y.; Yang, Z.; Tian, L.; Wu, S.; Wang, G.; Yu, Y.; Zhao, Q.; Chen, M.; et al. A hybrid and scalable brain-inspired robotic platform. Sci. Rep. 2020, 10, 1-13. [CrossRef] [PubMed]

18. Antonik, P.; Marsal, N.; Brunner, D.; Rontani, D. Human action recognition with a large-scale brain-inspired photonic computer. arXiv 2020, 1. [CrossRef]

19. Evans, J.S.B.T. Dual-Processing Accounts of Reasoning, Judgment, and Social Cognition. Annu. Rev. Psychol. 2008, 59, 255-278. [CrossRef] [PubMed]

20. Markram, H. The Human Brain Project. Sci. Am. 2012, 306, 50-55. [CrossRef] [PubMed]

21. Zhang, M.L.; Zhou, Z.H. ML-KNN: A lazy learning approach to multi-label learning. Pattern Recognit. 2007, 40, 2038-2048. [CrossRef]

22. Chang, D.Y. Applications of the extent analysis method on fuzzy AHP. Eur. J. Oper. Res. 1996, 95, 649-655. [CrossRef] 